\title{
Expression of inter- $\alpha$-trypsin inhibitor heavy chains in endometrium of cyclic and pregnant gilts
}

\author{
R. D. Geisert ${ }^{1}$, M. D. Ashworth ${ }^{1}$ and J. R. Malayer ${ }^{2}$ \\ ${ }^{1}$ Department of Animal Science, Oklahoma Agriculture Experiment Station \\ and ${ }^{2}$ Department of Physiological Sciences, College of Veterinary Medicine, \\ Oklahoma State University, Stillwater, OK 74078, USA
}

\begin{abstract}
Attachment of the placenta to the uterus in pigs involves extracellular interaction between the expanding trophoblastic membrane and the thick glycocalyx present on the uterine epithelial microvilli. Formation of complexes between members of inter- $\alpha$-trypsin inhibitor family may function in the maintenance of the extracellular matrix. This study investigated the change in the inter- $\alpha$-trypsin inhibitor heavy chains (ITIH1, ITIH2, ITIH3 and ITIH4) during the oestrous cycle and early pregnancy in pigs. Gene expression of ITIH1, ITIH2, ITIH3 and ITIH4 was detected in the endometrium of cyclic and pregnant
\end{abstract}

gilts; however, gene expression of ITIH was not altered throughout the oestrous cycle or early pregnancy. Western blot analysis with an ITIH antiserum identified the possible linkage forms of ITIH with the serine protease inhibitor, bikunin. Pregnancy altered the release of the various inter$\alpha$-inhibitor forms from the endometrium during the period of trophoblastic attachment. The results from this study indicate that the inter- $\alpha$-trypsin inhibitor family plays an important role in maintenance of the uterine surface glycocalyx during placental attachment in pigs.

\section{Introduction}

Survival of developing pig embryos within the uterus is dependent upon formation of an epitheliochorial type of placental attachment to the uterine surface. Pig conceptuses initiate attachment (days 13-18) to the thick glycocalyx present on the apical border of the surface epithelium after rapid expansion of their trophoblastic membrane on day 12 of pregnancy (King et al., 1982; Stroband and Van der Lende, 1990; Geisert and Yelich, 1997). Elongation and expansion of the trophoblastic membrane of the conceptus involves changes in cellular morphology through activation of many embryonic factors (Yelich et al., 1997a,b) and the presentation of uterine adhesion factors on the epithelial surface that permit continuous attachment of the placenta throughout gestation (Bowen et al., 1996; Jaeger et al., 2001). During adhesion of the trophectoderm to the uterine epithelial apical surface, a localized increase in transcapillary transport (Keys and King, 1988) as well as an overall increase in uterine blood flow occurs (Ford and Christenson, 1979) concurrently with conceptus synthesis of oestrogen (Ford et al., 1982; Geisert et al., 1982) needed for maintenance of the corpora lutea and establishment of pregnancy in pigs.

Email: geisert@okstate.edu
Many of the endometrial responses evoked by the developing pig conceptuses during this period of early development and uterine attachment resemble the acute phase response induced during generalized tissue inflammation (Salier et al., 1996; Geisert and Yelich, 1997). A glycoprotein member of the acute phase proteins, inter$\alpha$-trypsin inhibitor heavy chain 4 (ITIH4), has been isolated and characterized in the endometrium of pigs (Geisert et al., 1998). ITIH4 is only one member of the inter- $\alpha$-trypsin inhibitor family of protease inhibitors. The inter- $\alpha$-trypsin inhibitor family is composed of four heavy chains (ITIH1, ITIH2, ITIH3 and ITIH4) and one light chain, bikunin (Salier et al., 1996). Linkage of the various family members is proposed to be involved with stabilization of the extracellular matrix (Bost et al., 1998). Binding of bikunin to ITIH occurs in three forms, pre- $\alpha$ inhibitor $(\mathrm{P} \alpha \mathrm{I})$, inter- $\alpha$-like inhibitor $(\mathrm{I} \alpha \mathrm{LI})$ and inter- $\alpha$ inhibitor $(|\alpha|) . P \alpha \mid$ is a complex of bikunin bound to a single heavy chain of ITIH3; I $\alpha \mathrm{LI}$ is composed of bikunin and ITIH2 (Enghild et al., 1991); and $|\alpha|$ is formed by covalent binding of bikunin with two heavy chains, ITIH1 and ITIH2 (Bost et al., 1998). Attachment of bikunin to the heavy chains occurs through binding to a chondroitin sulphate chain. The serine protease inhibitory activity of $|\alpha|$ complex originates from bikunin, a $30 \mathrm{kDa}$ serine protease inhibitor containing two kunitz-type inhibitory domains (Xu et al., 1998), as the heavy chains are devoid of protease inhibitory activity. ITIH4 is unique from other ITIH as the Asp-Pro-His-Phe-Ile-Ile sequence for binding 
to bikunin is absent (Enghild et al., 1989; Salier et al., 1996; Bost et al., 1998) and, in contrast to the other ITIH, is a substrate for the plasma serine protease kallikrein (Nishimura et al., 1995).

As ITIH function as hyaluronic binding proteins, it has been proposed that $|\alpha|, \mid \alpha \mathrm{LI}$ and P $\alpha \mid$ stabilize the extracellular matrix (Bost et al., 1998). Evidence for a role of the ITI family in expansion of the cumulus-oocyte complex (Chen et al., 1994, 1996) supports a principal function of the ITI family in matrix stabilization through interaction with hyaluronic acid. The non-invasive, superficial epitheliochorial placentation in pigs is associated with a reduction in the uterine epithelial glycocalyx between the interdigitating trophoblastic and uterine epithelial microvilli (Dantzer, 1985). Although there is limited information concerning the apical interactions between the trophoblast and uterine surface epithelium, results indicate that changes in the cellular apical glycocalyx play a major role in initial trophoblastic attachment (Bowen et al., 1996; Jaeger et al., 2001). Detection of ITIH4 (Geisert et al., 1998) and bikunin (Hettinger et al., 2001) in the endometrium of pigs indicate that the $|\alpha|$ family may be involved with maintenance of the uterine apical glycocalyx necessary for trophoblastic attachment in pigs (Stroband and Van der Lende, 1990). The aim of the present study was to evaluate endometrial gene expression of ITIH1, ITIH2, ITIH3 and ITIH4 and the presence of $P \alpha|,| \alpha \mid$ and $\mid \alpha L I$ in the uterus during the oestrous cycle and early pregnancy of pigs.

\section{Materials and Methods}

\section{Animals}

Research was conducted in accordance with the Guiding Principles for Care and Use of Animals promoted by the Society for the Study of Reproduction and approved by the Oklahoma State Institutional Animal Care and Use Committee. Cyclic, large white gilts of similar age (8-10 months) and weight (100-130 kg) were examined twice each day for oestrous behaviour using intact boars. The onset of oestrus was considered as day 0 of the oestrous cycle. Gilts that were to be mated were bred naturally with fertile boars at the first detection of oestrus and $12 \mathrm{~h}$ later.

Cyclic gilts $(n=18)$ were hysterectomized on days 0 , $5,10,12,15$ or 18 of the oestrous cycle, whereas pregnant gilts $(n=12)$ were hysterectomized on days 10,12 , 15 or 18 of gestation as described by Gries et al. (1989). After surgical removal of the uterine horns as described by Gries et al. (1989), uterine flushings were obtained by isolating one uterine horn and flushing with $20 \mathrm{ml}$ of PBS ( $\mathrm{pH}$ 7.4). Uterine flushings were placed on ice until centrifugation $\left(2500 \mathrm{~g}, 10 \mathrm{~min}, 4^{\circ} \mathrm{C}\right)$. After flushing, the uterine horn was cut along its antimesometrial border; the endometrium was collected, snap frozen in liquid nitrogen and stored at $-80^{\circ} \mathrm{C}$. The remaining uterine horn was immediately placed in a sterile container and transported on ice for explant culture. Endometrium was removed from the mesometrial side of the uterine horn and cut into $4 \mathrm{~mm} \times 4 \mathrm{~mm}$ sections. A total of $0.5 \mathrm{~g}$ explant tissue was placed in $15 \mathrm{ml}$ Dulbecco's modified Eagle's medium (DMEM) (Gibco/Life Sciences, Gaithersburg, MD) and 2\% (v/v) antibiotic-antimycotic (Gibco/Life Sciences). After an initial incubation for $3 \mathrm{~h}$, medium was replaced with fresh medium to remove serum leaching from the tissue. Endometrial explant cultures were incubated in air on a rocking platform (four cycles per min) for an additional $24 \mathrm{~h}$ in DMEM at $37^{\circ} \mathrm{C}$. Endometrial explant culture medium was centrifuged at $2500 \mathrm{~g}$ for $10 \mathrm{~min}$ at $4^{\circ} \mathrm{C}$. Endometrial tissue, uterine flushings and endometrial explant medium were stored at $-80^{\circ} \mathrm{C}$ until analysed.

\section{Western blot analysis}

Uterine flushings and endometrial explant culture media were analysed by western blot analysis, as described by Geisert et al. (1995). Polypeptides in uterine flushings and explant culture medium (50 $\mu \mathrm{g}$ total protein) were separated by $12.5 \%$ one-dimensional SDS-PAGE and immediately transferred to polyvinylidene fluoride membrane (Millipore Corporation, Bedford, MA). After electroblotting, the membranes were washed, blocked and incubated with a 1:750 dilution of sheep first antibody raised against human inter- $\alpha$-trypsin inhibitor (The Binding Site, Inc., San Diego, CA). Sheep nonimmunized serum was run as a negative control. Immunoreactive polypeptides were detected using the Bio-Rad Immuno-Blot kit (Bio-Rad, Hercules, CA) according to the manufacturer's specifications.

\section{Endometrial RNA extraction}

Total RNA was isolated from endometrial tissue using TRIzol reagent (Gibco/Life Sciences). Approximately $0.5 \mathrm{~g}$ of endometrial tissue was homogenized in $5 \mathrm{ml}$ TRIzol reagent using a Virtishear homogenizer (Virtis Co. Inc., Gardiner, NY). RNA pellets were rehydrated with $10 \mathrm{mmol}^{\text {Tris I }} \mathrm{I}^{-1}, 1 \mathrm{mmol}$ EDTA I-1 $(\mathrm{pH} \mathrm{7.4)}$ and stored at $-80^{\circ} \mathrm{C}$ until further analysis. Total RNA was quantified using a spectrophotometer at an absorbance of $260 \mathrm{~nm}$, whereas the purity was determined based on 260:280 nm ratios. Integrity of the RNA was examined via gel electrophoresis.

Total RNA was reverse transcribed to cDNA using Moloney murine leukaemia virus reverse transcriptase (Promega Corporation, Madison, WI). The quality of endometrial cDNA was verified by amplifying glyceraldeyde-3-phosphate dehydrogenase as described by Yelich et al. (1997a). ITIH1, ITIH2 and ITIH3 primer construction,
optimization and sequencing

ITIH1, ITIH2 and ITIH3 primers were designed from pig cDNA sequences available in GenBank to determine 
Table 1. PCR primer and probe sequences used for quantitative RT-PCR

\begin{tabular}{|c|c|c|c|}
\hline Gene & & Forward primer/reverse primer/probe & GenBank accession number \\
\hline ITIH1 & $\begin{array}{l}\text { Forward } \\
\text { Reverse } \\
\text { Probe }\end{array}$ & $\begin{array}{l}\text { 5'-TGACTGGCGTGGACACTGA-3' } \\
\text { 5'-GCACAGGGTGTCCTCTTTCTG-3' } \\
\text { 5'-CCCCACTTCATCATCCGCGTGC-3' }\end{array}$ & Y11546 \\
\hline ITIH2 & $\begin{array}{l}\text { Forward } \\
\text { Reverse } \\
\text { Probe }\end{array}$ & $\begin{array}{l}\text { 5'-CGCGGTAGGACCTTCAGTGA-3' } \\
\text { 5'-GAAGTGCGGGTCATTTTCGA-3' } \\
\text { 5'-AGGTAATGCCTCCTCCACACGTGATGA-3' }\end{array}$ & Y11545 \\
\hline ITIH3 & $\begin{array}{l}\text { Forward } \\
\text { Reverse } \\
\text { Probe }\end{array}$ & $\begin{array}{l}\text { 5'-TGGTTTGTTCACGACAATGG-3' } \\
\text { 5'-AGGACGACTCTGTCGATCGG-3' } \\
\text { 5'-TGTCCCCGACCTGTTCTGAGTGG-3' }\end{array}$ & D84320 \\
\hline ITIH4 & $\begin{array}{l}\text { Forward } \\
\text { Reverse } \\
\text { Probe }\end{array}$ & $\begin{array}{l}\text { 5'-TGCGTACAAGTGGAAGGAAACA-3' } \\
\text { 5'-CCCGCCTTGTCCATGGT-3' } \\
\text { 5'-TCTACTCAGTGATGCCCGGCCTCAA-3' }\end{array}$ & U43164 \\
\hline
\end{tabular}

ITIH: inter- $\alpha$-trypsin inhibitor heavy chain.

whether they were expressed in the endometrium of pigs. The nucleotide sequence of pig ITIH1 (GenBank Y11546) was used to construct the forward 5'-GCTGGAGAACTATGTCGAACGC-3' (1276-1297 bp) and reverse 5'-AAGTAGGTGCCCTCATGCTTCC-3' (1773-1794 bp) primers. The nucleotide sequence of pig ITIH2 (GenBank Y11545) was used to construct forward 5'-AGTCTTGCTCAGGTACCC-3' (1948-1969 bp) and reverse 5'-TCGACATTGATCGGATGCTTC-3' (2504-2524 bp) primers. The forward 5'-TGGTTTGTTCACGACAATGG-3' and reverse $5^{\prime}$-TCACCTTGGCCTTTATTATGC-3' primers for ITIH3 were designed from partial sequences of pig liver ITIH3 mRNA (GenBank D84319). The PCR conditions were optimized by pooling CDNA from cyclic and pregnant endometrium of all days and amplifying with $0.6 \mathrm{U}$ Taq DNA polymerase and its supplied $\mathrm{MgCl}_{2}$-free buffer (Promega, Madison, WI) and a $3 \times 2 \times 3$ factorial combination of primer $\left(50,150,250 \mathrm{nmol} \mathrm{I^{-1 }}\right)$, deoxynucleotide triphosphates (dNTPs; 50 or $100 \mu \mathrm{mol} \mathrm{I}{ }^{-1}$ ), and $\mathrm{MgCl}_{2}\left(1.25,2.50\right.$ or $\left.3.75 \mathrm{mmol} \mathrm{I}^{-1}\right)$ as described by Yelich et al. (1997a). Conditions used for ITIH1, ITIH2 and $\mathrm{ITIH} 3$ gene amplification were $5 \mathrm{nmol} \mathrm{I}^{-1}$ of template in $1.25 \mathrm{mmol} \mathrm{MgCl} \mathrm{I}^{-1}, 100 \mu \mathrm{mol} d N T P s \mathrm{I}^{-1}$ and $50 \mathrm{nmol}$ primer $\mathrm{I}^{-1}$. The Recombinant DNA/Protein Research Facility at Oklahoma State University sequenced amplicons from the PCR endometrial cDNA.

\section{Quantitative reverse transcriptase-polymerase chain reaction}

Endometrial gene expressions for ITIH1, ITIH2, ITIH3 and ITIH4 were quantified by using the one-step RT-PCR reaction following the manufacturer's recommendations for TaqMan ${ }^{\circledR}$ Gold RT-PCR kit (P/N N808-0233) (PE Applied Biosystems, Foster City, CA), as described by Hettinger et al. (2001). Information concerning cDNA location and the sequence of the primers and probe for
$I T I H 1, I T I H 2, I T I H 3$ and ITIH4 are presented (Table 1). The total reaction volume of $50 \mu \mathrm{l}$ contained $200 \mathrm{nmol}$ forward primer $\mathrm{I}^{-1}, 200 \mathrm{nmol}$ reverse primer $\mathrm{I}^{-1}$, $100 \mathrm{nmol}$ fluorescent labelled probe $\mathrm{I}^{-1}$ and $100 \mathrm{ng}$ of total RNA. The PCR amplification was carried out in the $A B I$ PRISM $^{\circledR} 7700$ sequence detection system (Applied Biosystems). Thermal cycling conditions were $50^{\circ} \mathrm{C}$ for $2 \mathrm{~min}, 95^{\circ} \mathrm{C}$ for $10 \mathrm{~min}$ followed by repetitive cycles of $95^{\circ} \mathrm{C}$ for $15 \mathrm{~s}$ and $60^{\circ} \mathrm{C}$ for $1 \mathrm{~min}$. Ribosomal 18S RNA (18S, RNA Control Kit, 43108993E, Applied Biosystems) was run as a control for RNA loading. Reverse transcriptase was omitted from sample PCR wells to determine possible contribution of sample genomic DNA contamination to amplification. Amplification of curve of genomic DNA was similar to the no template control.

After RT-PCR, gene amplification was quantified by setting the threshold cycle $\left(C_{\mathrm{T}}\right)$ in the geometric region of the plot after examining the semi-log view of the amplification plot. Relative quantification of ITIH gene expression was evaluated using the comparative $C_{\mathrm{T}}$ method, as described by Hettinger et al. (2001). The $\Delta C_{\mathrm{T}}$ value is determined by subtracting the $I T I H C_{\mathrm{T}}$ of each sample from its ribosomal $18 \mathrm{~S} C_{\mathrm{T}}$ value (Table 2 ). Calculation of $\Delta \Delta C_{\mathrm{T}}$ involves using the highest sample $\Delta C_{\mathrm{T}}$ value as an arbitrary constant to subtract from all other $\Delta C_{\mathrm{T}}$ sample values. Fold changes in gene expression of ITIH is determined by evaluating the expression, $2^{-\Delta \Delta C t}$.

\section{Statistical analysis}

Data were analysed by least-squares ANOVA using the General Linear Models of the Statistical Analysis System (SAS, 1988). The statistical model used to analyse endometrial expression of ITIH genes included the effects of day, reproductive status (cyclic and pregnant), and day $\times$ reproductive status. 
Table 2. Comparison of endometrial expression of inter- $\alpha$-trypsin inhibitor heavy chain (ITIH1, ITIH2, ITIH3 and ITIH4) genes across days of the oestrous cycle and early pregnancy using the comparative $C_{\mathrm{T}}$ method

\begin{tabular}{|c|c|c|c|c|c|c|c|}
\hline Target & Status & Day & Average target $C_{\mathrm{T}}{ }^{\mathrm{a}}$ & Average $18 \mathrm{~S}$ rRNA $C_{\mathrm{T}}{ }^{\mathrm{a}}$ & $\Delta C_{\mathrm{T}}^{\mathrm{b}, \mathrm{d}}$ & $\Delta \Delta C_{\mathrm{T}}^{\mathrm{c}}$ & Fold change \\
\hline \multirow[t]{10}{*}{ ITIH1 } & Cyclic & 0 & $26.81 \pm 1.74$ & $13.54 \pm 0.19$ & $13.27 \pm 1.67$ & -0.91 & 1.88 \\
\hline & Cyclic & 5 & $27.70 \pm 2.10$ & $13.52 \pm 0.27$ & $14.18 \pm 2.00$ & 0.00 & 1.00 \\
\hline & Cyclic & 10 & $26.81 \pm 1.10$ & $13.24 \pm 0.31$ & $13.57 \pm 1.22$ & -0.61 & 1.53 \\
\hline & Pregnant & 10 & $25.82 \pm 0.59$ & $13.20 \pm 0.17$ & $12.62 \pm 0.60$ & -1.56 & 2.95 \\
\hline & Cyclic & 12 & $27.36 \pm 1.51$ & $13.21 \pm 0.45$ & $14.15 \pm 1.10$ & -0.03 & 1.02 \\
\hline & Pregnant & 12 & $26.54 \pm 0.95$ & $13.39 \pm 0.08$ & $13.15 \pm 0.89$ & -1.03 & 2.04 \\
\hline & Cyclic & 15 & $26.69 \pm 1.12$ & $12.96 \pm 0.11$ & $13.73 \pm 1.22$ & -0.45 & 1.37 \\
\hline & Pregnant & 15 & $26.91 \pm 0.70$ & $13.59 \pm 0.09$ & $13.32 \pm 0.77$ & -0.83 & 1.78 \\
\hline & Cyclic & 18 & $26.69 \pm 2.24$ & $12.96 \pm 0.15$ & $13.73 \pm 1.73$ & -0.42 & 1.34 \\
\hline & Pregnant & 18 & $26.92 \pm 1.14$ & $13.58 \pm 0.10$ & $13.34 \pm 0.89$ & -0.84 & 1.79 \\
\hline \multirow[t]{10}{*}{ ITIH2 } & Cyclic & 0 & $30.84 \pm 1.94$ & $13.54 \pm 0.19$ & $17.30 \pm 2.09$ & -2.30 & 4.92 \\
\hline & Cyclic & 5 & $33.12 \pm 2.14$ & $13.52 \pm 0.27$ & $19.60 \pm 1.90$ & 0.00 & 1.00 \\
\hline & Cyclic & 10 & $31.31 \pm 1.05$ & $13.24 \pm 0.31$ & $18.07 \pm 1.07$ & -1.53 & 2.89 \\
\hline & Pregnant & 10 & $32.08 \pm 1.05$ & $13.20 \pm 0.17$ & $18.88 \pm 0.89$ & -0.72 & 1.65 \\
\hline & Cyclic & 12 & $32.17 \pm 1.43$ & $13.21 \pm 0.45$ & $18.96 \pm 1.27$ & -0.64 & 1.56 \\
\hline & Pregnant & 12 & $29.71 \pm 0.92$ & $13.39 \pm 0.08$ & $16.32 \pm 0.83$ & -3.28 & 9.71 \\
\hline & Cyclic & 15 & $31.33 \pm 1.32$ & $12.96 \pm 0.11$ & $18.37 \pm 1.35$ & -1.23 & 2.35 \\
\hline & Pregnant & 15 & $31.06 \pm 0.47$ & $13.59 \pm 0.09$ & $17.47 \pm 0.49$ & -2.13 & 4.38 \\
\hline & Cyclic & 18 & $30.95 \pm 0.93$ & $12.96 \pm 0.15$ & $17.99 \pm 0.57$ & -1.61 & 3.05 \\
\hline & Pregnant & 18 & $31.52 \pm 0.58$ & $13.58 \pm 0.10$ & $17.94 \pm 0.60$ & -1.66 & 3.16 \\
\hline \multirow[t]{10}{*}{ ITIH3 } & Cyclic & 0 & $26.97 \pm 1.08$ & $13.54 \pm 0.19$ & $13.42 \pm 0.93$ & -0.52 & 1.43 \\
\hline & Cyclic & 5 & $26.25 \pm 0.81$ & $12.96 \pm 0.12$ & $13.29 \pm 0.81$ & -0.65 & 1.57 \\
\hline & Cyclic & 10 & $26.68 \pm 0.53$ & $13.65 \pm 0.07$ & $13.03 \pm 0.50$ & -0.91 & 1.88 \\
\hline & Pregnant & 10 & $26.92 \pm 0.60$ & $12.97 \pm 0.04$ & $13.94 \pm 0.55$ & 0.00 & 1.00 \\
\hline & Cyclic & 12 & $26.56 \pm 0.43$ & $13.36 \pm 0.24$ & $13.21 \pm 0.41$ & -0.73 & 1.66 \\
\hline & Pregnant & 12 & $25.69 \pm 0.17$ & $13.31 \pm 0.15$ & $12.37 \pm 0.21$ & -0.57 & 1.48 \\
\hline & Cyclic & 15 & $27.32 \pm 0.56$ & $13.51 \pm 0.21$ & $13.81 \pm 0.36$ & -0.13 & 1.09 \\
\hline & Pregnant & 15 & $26.13 \pm 0.49$ & $13.64 \pm 0.20$ & $12.42 \pm 0.26$ & -0.52 & 1.43 \\
\hline & Cyclic & 18 & $28.28 \pm 0.35$ & $14.93 \pm 0.61$ & $13.34 \pm 0.50$ & -0.60 & 1.52 \\
\hline & Pregnant & 18 & $26.74 \pm 0.48$ & $13.51 \pm 0.15$ & $13.23 \pm 0.61$ & -0.71 & 1.64 \\
\hline \multirow[t]{10}{*}{ ITIH4 } & Cyclic & 0 & $30.94 \pm 0.36$ & $13.54 \pm 0.19$ & $17.40 \pm 0.36$ & -0.55 & 1.46 \\
\hline & Cyclic & 5 & $30.86 \pm 0.17$ & $13.52 \pm 0.27$ & $17.34 \pm 0.17$ & 0.61 & 1.53 \\
\hline & Cyclic & 10 & $30.80 \pm 0.26$ & $13.24 \pm 0.31$ & $17.56 \pm 0.26$ & -0.39 & 1.31 \\
\hline & Pregnant & 10 & $30.81 \pm 0.18$ & $13.20 \pm 0.17$ & $17.61 \pm 0.19$ & -0.34 & 1.27 \\
\hline & Cyclic & 12 & $29.81 \pm 0.64$ & $13.21 \pm 0.45$ & $16.60 \pm 0.63$ & -1.35 & 2.55 \\
\hline & Pregnant & 12 & $30.79 \pm 0.33$ & $13.39 \pm 0.08$ & $17.40 \pm 0.33$ & -0.55 & 1.46 \\
\hline & Cyclic & 15 & $30.44 \pm 0.70$ & $12.96 \pm 0.11$ & $17.48 \pm 0.70$ & -0.47 & 1.39 \\
\hline & Pregnant & 15 & $30.47 \pm 0.62$ & $13.59 \pm 0.09$ & $16.88 \pm 0.62$ & -1.07 & 2.10 \\
\hline & Cyclic & 18 & $30.91 \pm 0.64$ & $12.96 \pm 0.15$ & $17.95 \pm 0.64$ & 0.00 & 1.00 \\
\hline & Pregnant & 18 & $30.28 \pm 0.52$ & $13.58 \pm 0.10$ & $16.70 \pm 0.52$ & -1.25 & 2.38 \\
\hline
\end{tabular}

${ }^{a} C_{T}=$ Cyclic threshold: cycle number where amplification crosses the threshold set in the geometric portion of the amplification curve.

${ }^{\mathrm{b}} \Delta C_{\mathrm{T}}=\mathrm{ITIH}-18 \mathrm{~S}$ ribosomal $C_{\mathrm{T}}$ : normalization of PCR cycles for the ITIH target with $18 \mathrm{~S}$ ribosomal RNA.

${ }^{\mathrm{c}} \Delta \Delta C_{\mathrm{T}}=$ Mean $\Delta C_{\mathrm{T}}$ - highest mean $\Delta C_{\mathrm{T}}$ value: the mean value on day 10 of pregnancy (highest $\Delta C_{\mathrm{T}}$; lowest gene expression for ITIH1) was used as a calibrator for ITIH1, on day 5 cycling for ITIH2 and ITIH4, for ITIH3 and for ITIH4 to set the baseline for comparing mean differences in $\Delta C_{\mathrm{T}}$ values across all days.

${ }^{d}$ Comparison of day, status and status by day effects were analysed with the normalized $\Delta C_{T}$ values. No significant differences were detected for day, status or status by day.

\section{Results}

\section{Western blot analysis of uterine $l \alpha l$}

The human inter- $\alpha$-trypsin inhibitor antibody recognized heavy chains of $|\alpha|$ in pig serum (Fig. 1). Antiserum detected reactive products in pig serum that were approximately $120-140 \mathrm{kDa}$ and $>200 \mathrm{kDa}$, which are consistent with the $M_{\mathrm{r}}$ of $|\alpha|$ forms described in human serum (Rouet et al., 1992). The three serum products detected by the antiserum correspond to the putative $M_{\mathrm{r}}$ of $|\alpha|, \mid \alpha \mathrm{LI}$ and P $\alpha \mid$. However, it is possible that the polyclonal antiserum used could also detect ITIH4 at the $120 \mathrm{kDa}$ band. Antiserum detected similar bands of $|\alpha|$ in endometrial culture medium from both cyclic and 
pregnant gilts (Fig. 1a). With the exception of oestrus, the three $|\alpha|$ reactive products were detected throughout the oestrous cycle in cyclic gilts, but expression was greatly attenuated in pregnant gilts after day 10 of gestation.

A band $|\alpha|$ at $>200 \mathrm{kDa}$ was detected in uterine flushings on day 5 and day 10 of the oestrous cycle (Fig. 1b). However, only very faint reactive products were detected in uterine flushings of cyclic gilts at oestrus and after day 10 of the oestrous cycle. The $200 \mathrm{kDa}$ band was also faint to absent in uterine flushings from pregnant gilts but in contrast to cyclic gilts lower $M_{\mathrm{r}}$ products of approximately $60-50 \mathrm{kDa}$ were detected in uterine flushings on days 12,15 and 18 of the oestrous cycle.

\section{Quantitative RT-PCR analysis of endometrial $m R N A$ expression of ITIH1, ITIH2, ITIH3 and ITIH4}

Primers designed to ITIH1 and ITIH2 amplified an endometrial RT-PCR product that had 93 and 100\% similarity to pig ITIH1 and ITIH2 cDNA sequences published in GenBank (Y11546 and Y11545). Endometrium expressed a $182 \mathrm{bp}$ amplicon that had 100\% similarity to pig liver ITIH3 (GenBank D84319). Geisert et al. (1998) established endometrial gene expression for ITIH4. Endometrial expression of mRNA for ITIH1, ITIH2, ITIH3 and ITIH4 during the oestrous cycle and early pregnancy was quantified with real-time RT-PCR. Quantitative ITIH gene expression was evaluated using the comparative $C_{\mathrm{T}}$ (threshold cycle) method (see Table 2). Ribosomal 18S RNA was used to normalize each sample for variation in RNA loading. No day, status or status by day interaction was detected for PCR cycle number $\left(\Delta C_{\mathrm{T}}\right)$ with endometrial expression of ITIH1, ITIH2, ITIH3 or ITIH4 genes (Table 2).

\section{Discussion}

The non-invasive form of implantation in pigs results from endometrial secretion of protease inhibitors that regulate the highly invasive activity of the trophoblast (Roberts et al., 1993). Therefore, although pig conceptuses are inherently highly proteolytic and invasive outside the uterine environment (Samuel and Perry, 1972), endometrial secretion of protease inhibitors only permits trophoblast attachment to the thick glycocalyx on the apical uterine surface epithelium (Stroband and Van der Lende, 1990). Placentation in pigs is associated with a reduction in the uterine epithelial glycocalyx as well as interdigitation of the trophoblastic and uterine microvilli (Danzter, 1985). Attachment of the trophoectoderm to the uterine surface glycocalyx can induce intracellular pathways that play a major role in pig placental attachment and embryo survival (Bowen et al., 1996; Jaeger et al., 2001).

Support for a principal function of the $|\alpha|$ family in matrix stabilization through its interaction with hyaluronic acid has been described for expansion of the (a)

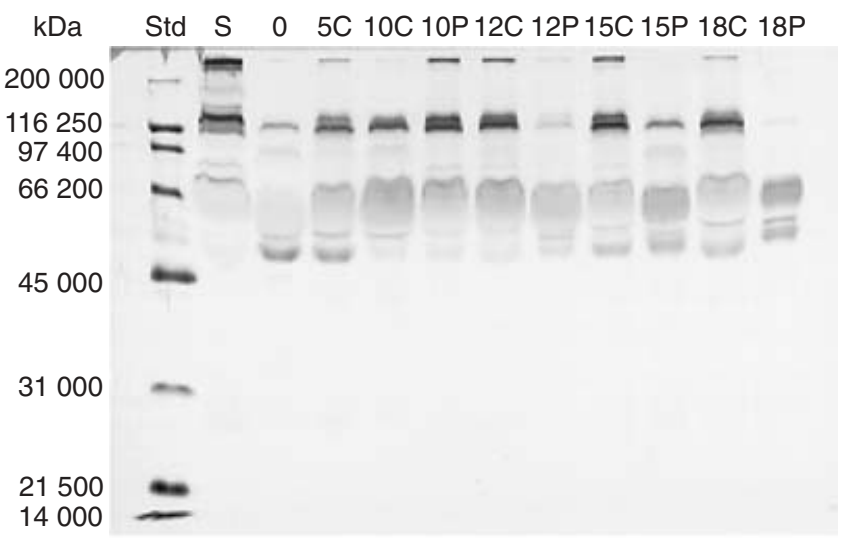

(b)

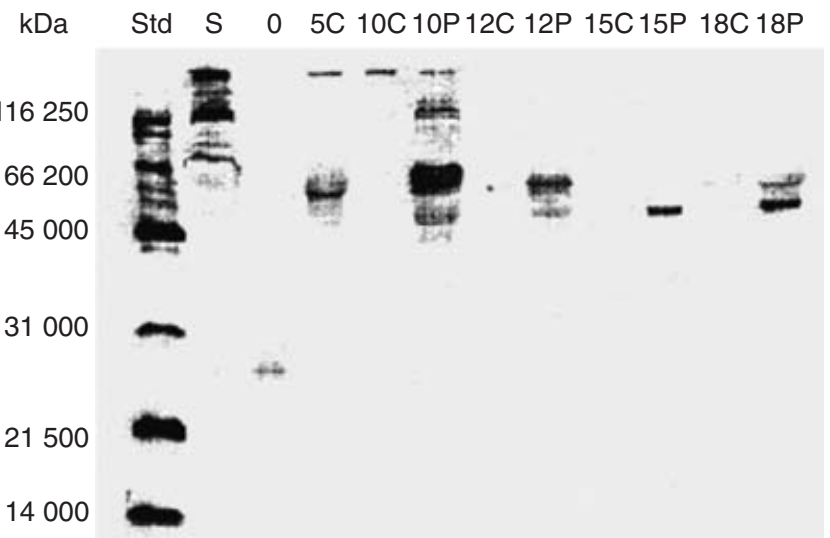

Fig. 1. Representative western blot analysis of protein $(50 \mu \mathrm{g})$ from (a) endometrial explant culture media and (b) uterine flushings on days of the oestrous cycle $(\mathrm{C})$ and early pregnancy $(\mathrm{P})$ in pigs using antiserum against human inter- $\alpha$-trypsin inhibitor. Western blots were performed in triplicate to analyse the three animals per day in each status group. S: pig serum; Std: molecular mass standard.

cumulus-oocyte complex (Chen et al., 1994). Identification of endometrial ITIH4 (Geisert et al., 1998) and bikunin (Hettinger et al., 2001) indicated that the $|\alpha|$ family is present in the pig uterus. The current study clearly establishes presence of the $|\alpha|$ family in the uterus and provides evidence that $|\alpha|$ may function to stabilize the glycocalyx at the endometrial-placental interface during pregnancy in pigs. The release of bikunin during early pregnancy (Hettinger et al., 2001) may function to permit ITIH binding with hyaluronic acid and through its release in the interface between the conceptus and uterine epithelium prevent uterine invasion by the proteolytic conceptuses during placental attachment. Inactivation of the bikunin gene causes infertility in mice through disruption of the cumulus oophorus (Zhuo et al., 2001) and this finding indicates that the breakdown in the pig uterine glycocalyx and embryonic loss that occurs after early (days 9-10) exposure to oestrogen (Blair et al., 1991) may result from altered $|\alpha|$ production during 
early stages of placentation. During the critical period of placental attachment in pigs on days 15-18 of pregnancy there is a 70 -fold increase in endometrial bikunin gene expression (Hettinger et al., 2001), which indicates that there is an important role for bikunin and the $|\alpha|$ heavy chains during the period of conceptus attachment to the uterine luminal surface.

Detection of immunoproducts of $>200$ and 140$120 \mathrm{kDa}$ in endometrial culture medium by western blot analysis indicates that $|\alpha|, P \alpha \mid$ and $\mid \alpha L I$ are present in the uterine endometrium of pigs. The two bands of approximately 140 and $120 \mathrm{kDa}$, which are present in pig serum, are consistent with the size of $\mathrm{I} \alpha \mathrm{LI}$ and $\mathrm{P} \alpha \mathrm{l}$ (Rouet et al., 1992). However, ITIH4 also has $M_{\mathrm{r}}$ of $120 \mathrm{kDa}$ that would also be detected by the $|\alpha|$ antibody used in the study. Immunoreactive bands of $M_{\mathrm{r}}$ similar to $|\alpha|$, $P \alpha \mid$ and $\mid \alpha \mathrm{LI}$ were also detected in endometrial culture medium using antiserum to human bikunin (Hettinger et al., 2001). These results indicate that the immunoproducts detected with $|\alpha|$ antibody represent bikunin bound with ITIH. It is possible that plasma $|\alpha|$ could contribute to the detection of uterine $|\alpha|$. However, the results of the present study demonstrate endometrial gene expression of all ITIH during the oestrous cycle and early pregnancy.

Although endometrial gene expression for ITIH was not different across the days of the oestrous cycle and early pregnancy, a distinct change in the release of the $|\alpha|$ family members was evident with in vitro culture of endometrium from cyclic and pregnant gilts. Detection of $|\alpha|, \mid \alpha \mathrm{LI}$ and $\mathrm{P} \alpha \mid$ was greatly reduced in endometrial culture medium from pregnant gilts after day 12 of pregnancy. These results indicate that during attachment, the conceptuses either stabilize the release of the glycoproteins from the endometrial surface or proteolytic enzymes released by the conceptuses cleave $|\alpha|, P \alpha \mid$ and $I \alpha \mathrm{LI}$. The alteration of the glycoproteins in culture medium was also observed in uterine flushings where detection of $|\alpha|, P \alpha \mid$ and $|\alpha L|$ was reduced after day 10 of pregnancy. The presence of immunoproducts of lower $M_{\mathrm{r}}$ in uterine flushings of pregnant gilts indicates conceptusinduced proteolytic cleavage of ITIH. Cleavage of ITIH4 occurs specifically through activation of kallikrein that occurs in vivo after day 10 of the oestrous cycle or pregnancy (Geisert et al., 1998; Vonnahme et al., 1999). ITIH4 is present on the uterine surface and glandular epithelium and is detected in endometrial culture medium (Geisert et al., 1995, 1998). Because ITIH4 does not contain protease inhibitory activity or bind bikunin like the other ITIH chains (Choi-Miura et al., 1995; Nishimura et al., 1995), ITIH4 must have a biological function unrelated to release of bikunin and protease inhibition. All ITIH contain a von Willebrand type-A domain that functions as a target for adhesion molecules (Salier et al., 1996). Endometrial synthesis of ITIH4 could assist in the extracellular matrix formation through binding to integrins, collagen, proteoglycans and heparin. Choi-
Miura et al. (2000) proposed that ITIH4 binds and suppresses the phagocytic activity of polymorphonuclear cells. Thus, ITIH4 may serve an immunological protective role within the pig uterus.

The importance of the alteration in uterine $|\alpha|, P \alpha \mid$ and $I \alpha \mathrm{LI}$ during pregnancy may reflect the release of bikunin during association of heavy chains with hyaluronate (Jessen et al., 1994). Although intact $|\alpha|$ (with bikunin) is able to bind to hyaluronate, bikunin is not associated with ITIH when bound to hyaluronate in extracellular physiological fluids (Jessen et al., 1994). Bost et al. (1998) suggested that there is first an ionic interaction of hyaluronic acid with $I \alpha \mathrm{l}$, which is followed by a substitution of hyaluronic acid for bikunin. The substitution would result in a complex consisting of heavy chains with only hyaluronic acid and the release of bikunin into extracellular fluids. The results of the present study indicate that such an alteration occurs during establishment of pregnancy and placentation in pigs. Hettinger et al. (2001) documented a pregnancy-specific alteration of bikunin release during in vitro endometrial culture similar to the present results. Furthermore, specific in vitro release of bikunin was only detected between day 15 and day 18 of pregnancy. Jessen et al. (1994) indicated that hyaluronate-bound $|\alpha|$ can be partly degraded in vivo by trypsin-like proteases, such as plasminogen activator. Presence of low $M_{\mathrm{r}}$ glycoproteins in the uterine flushings of pregnant gilts between day 10 and day 18 in the present study and the large increase in conceptus plasminogen activator release during placental attachment (Fazleabas et al., 1983) provide evidence for cleavage of $|\alpha|$ during placental attachment in pigs. The combination of the results of the present study and other studies with the $|\alpha|$ family indicates the $|\alpha|$ family may have a physiological role in establishment of pregnancy in pigs.

The authors would like to thank S. Welty for the care and feeding of the animals used in the study. Appreciation is expressed to M. Allen and A. Hettinger for their assistance with surgeries and T. Pratt for technical assistance. The authors extend their thanks to the Oklahoma State University Recombinant DNA/Protein Resource Facility for the synthesis of synthetic nucleotides and DNA sequencing. This research was supported by NRICGP/USDA grant 98-35203-6224 and 2002-35203-12262 and Hatch Project OKL02465 awarded to R. D. Geisert. Manuscript approved for publication by the Director, Oklahoma Agriculture Experiment Station.

\section{References}

Blair RM, Geisert RD, Zavy MT, Short EC, Fulton RW and Yellin T (1991) Endometrial morphological and secretory alterations associated with embryonic mortality in gilts administered estradiol valerate on days 9 and 10 of gestation Biology of Reproduction 44 1063-1079

Bost F, Diarra-Mehrpour M and Martin JP (1998) Inter- $\alpha$-trypsin inhibitor proteoglycan family: a group of proteins binding and stabilizing the extracellular matrix European Journal of Biochemistry 222339 346 
Bowen JA, Bazer FW and Burghardt RC (1996) Spatial and temporal analyses of integrin and MUC-1 expression in porcine uterine epithelium and trophectoderm in vivo. Biology of Reproduction 55 1098-1106

Chen L, Mao SJT, McLean LR, Powers RW and Larsen WJ (1994) Proteins of the inter- $\alpha$-trypsin inhibitor family stabilize the cumulus extracellular matrix through their direct binding with hyaluronic acid Journal of Biological Chemistry 26928 282-28 287

Chen L, Zhang H, Powers RW, Russell PT and Larsen WJ (1996) Covalent linkage between proteins of the inter- $\alpha$-inhibitor family and hyaluronic acid is mediated by a factor produced by granulosa cells Journal of Biological Chemistry 27119 409-19 414

Choi-Miura N-H, Sano Y, Oda E, Nakano Y, Tobe T, Yanagishita T, Taniyama M, Katagire T and Tomita $\mathbf{M}$ (1995) Purification and characterization of a novel glycoprotein which has significant homology to heavy chains of inter- $\alpha$-trypsin inhibitor family from human plasma Journal of Biochemistry 117 400-407

Choi-Miura N-H, Takahashi K, Yoda M, Saito K, Hori M, Ozaki H, Mazda T and Tomita $\mathbf{M}$ (2000) The novel acute phase protein, IHRP, inhibits actin polymerization and phagocytosis of polymorphonuclear cells Inflammation Research 49 305-310

Dantzer V (1985) Electron microscopy of the initial stages of placentation in the pig Anatomy and Embryology 172 281-293

Enghild JJ, Thogersen IB, Pizzo SV and Salvesen G (1989) Analysis of inter$\alpha$-trypsin inhibitor, pre- $\alpha$-trypsin inhibitor, from human plasma Journal of Biological Chemistry 26415 975-15981

Enghild JJ, Salvesen G, Hefta SA, Thogersen IB, Rutherfurd S and Pizzo SV (1991) Chondroitin 4-sulfate covalently cross-links the chains of the human blood protein pre- $\alpha$-inhibitor Journal of Biological Chemistry 266 747-751

Fazleabas AT, Geisert RD, Bazer FW and Roberts RM (1983) Relationship between release of plasminogen activator and estrogen by blastocysts and secretion of plasmin inhibitor by uterine endometrium in the pregnant pig Biology of Reproduction 29 225-238

Ford SP and Christenson RK (1979) Blood flow to uteri of sows during the estrous cycle and early pregnancy: local effect of the conceptus on the uterine blood supply Biology of Reproduction 21 617-624

Ford SP, Christenson RK and Ford JJ (1982) Uterine blood flow and uterine arterial, venous and lumenal concentrations of oestrogens on days 11 , 13 , and 15 after oestrus in pregnant and non-pregnant sows Journal of Reproduction and Fertility 64 185-190

Geisert RD and Yelich JV (1997) Regulation of conceptus development and attachment in pigs Journal of Reproduction and Fertility Supplement 52 133-149

Geisert RD, Renegar RH, Thatcher WW, Roberts RM and Bazer FW (1982) Establishment of pregnancy in the pig. I. Interrelationships between preimplantation development of the pig blastocyst and uterine endometrial secretions Biology of Reproduction 27 925-939

Geisert RD, Dixon MJ, Pratt T, Schmitt RAM, Lessley BA and McCann JP (1995) Isolation and characterization of a $30 \mathrm{kDa}$ endometrial glycoprotein synthesized during the estrous cycle and early pregnancy in the pig Biology of Reproduction 53 942-954

Geisert RD, Yelich JV, Pratt T and Pomp D (1998) Expression of an inter- $\alpha-$ trypsin inhibitor heavy chain-like protein in the pig endometrium during the oestrous cycle and early pregnancy Journal of Reproduction and Fertility 114 35-43

Gries LK, Geisert RD, Zavy MT, Garrett JE and Morgan GL (1989) Uterine secretory alterations coincident with embryonic mortality in the gilt after exogenous estrogen administration Journal of Animal Science 67276 284

Hettinger AM, Allen MA, Zhang BR, Goad DW, Malayer JR and Geisert RD (2001) Presence of acute phase protein, bikunin, in the endometrium of gilts during estrous cycle and early pregnancy Biology of Reproduction 65 507-513

Jaeger LA, Johnson GA, KA H, Garlow JG, Burghardt RC, Spencer TE and Bazer FW (2001) Functional analysis of autocrine and paracrine signaling at the uterine-conceptus interface in pigs Reproduction Supplement 58 191-207

Jessen TE, Odum L and Johnsen AH (1994) In vivo binding of human inter- $\alpha$-trypsin inhibitor free heavy chains to hyaluronic acid Biological Chemistry Hoppe-Seyler 375 521-526

Keys JL and King GJ (1988) Morphological evidence for increased uterine vascular permeability at the time of embryonic attachment in the pig Biology of Reproduction 39 473-487

King GJ, Atkinson A and Robertson HA (1982) Implantation and early placentation in domestic ungulates Journal of Reproduction and Fertility Supplement 31 17-30

Nishimura H, Kakizaki I, Muta T, Sasaki N, Pu PX, Yamashita T and Nagasawa S (1995) cDNA and deduced amino acid sequence of human PK-120, a plasma kallikrein-sensitive glycoprotein FEBS Letters 357207 211

Roberts RM, Xie S and Trout WE (1993) Embryo-uterine interactions in pigs during week 2 of pregnancy Journal of Reproduction and Fertility Supplement 48 171-186

Rouet P, Daveau M and Salier J-P (1992) Electrophoretic pattern of the inter- $\alpha$-inhibitor family proteins in human serum, characterized by chain specific antibodies Biological Chemistry Hoppe-Seyler 3731019 1024

Salier J-P, Rouet P, Raguenez G and Daveau M (1996) The inter- $\alpha$-inhibitor family: from structure to regulation Biochemical Journal 315 1-9

Samuel CA and Perry JS (1972) The ultrastructure of pig trophoblast transplanted to an ectopic site in the uterine wall Journal of Anatomy 113 139-149

SAS/STAT (1988) User's guide. SAS Institute, Inc., Cary, North Carolina

Stroband HWJ and Van der Lende T (1990) Embryonic and uterine development during early pregnancy in pigs Journal of Reproduction and Fertility Supplement 40 261-277

Vonnahme KA, Malayer JR, Spivey HO, Ford SP, Clutter A and Geisert RD (1999) Detection of kallikrein gene expression and enzymatic activity in porcine endometrium during the estrous cycle and early pregnancy Biology of Reproduction 61 1235-1241

Yelich JV, Pomp D and Geisert RD (1997a) Detection of transcripts for retinoic acid receptors, retinol binding protein, and transforming growth factors during rapid trophoblastic elongation in the porcine conceptus Biology of Reproduction 57 126-134

Yelich JV, Pomp D and Geisert RD (1997b) Ontogeny of elongation and gene expression in the early developing porcine conceptuses Biology of Reproduction 57 1256-1264

Xu Y, Carr PD, Guss JM and Ollis DL (1998) The crystal structure of bikunin from the inter- $\alpha$-inhibitor complex: a serine protease inhibitor with two kunitz domains Journal of Molecular Biology 276 955-966

Zhuo L, Yoneda M, Zhao M, Yingsung W, Yoshida N, Kitagawa $Y$, Kawamura K, Suzuki T and Kimata K (2001) Defect in SHAP-hyaluronan complex causes severe female infertility: a study by inactivation of the bikunin gene in mice Journal of Biological Chemistry 276 76937696

Received 2 July 2003

First decision 5 August 2003.

Revised manuscript received 7 August 2003.

Accepted 7 August 2003. 